\title{
Evolução do espaço rural brasileiro
}

\author{
Luiz Sérgio Pires Guimarães
}

As condições naturais do território brasileiro favorecem o desenvolvimento de uma atividade agropecuária em larga escala. Com um relevo predominantemente plano, uma significativa diferenciação climática e sendo detentor das maiores reservas de água doce conhecidas, o Brasil se consolidou no mercado internacional como um dos grandes produtores de grãos, carnes e bioenergia do mundo contemporâneo. Essa trajetória da agropecuária nacional, embora tenha seu desenvolvimento ligado a condições naturais favoráveis, é, igualmente, indissociável dos condicionantes históricos, políticos, sociais e geográficos que traçaram o processo de construção do espaço rural brasileiro.

Com a quase totalidade do seu território situado na zona tropical e subtropical, o espaço rural brasileiro começa efetivamente a se estruturar a partir da introdução da monocultura da cana-de-açúcar, na Região Nordeste, no Século XVI (VALVERDE, 1985). Destinada ao mercado externo, essa lavoura era cultivada em larga escala, em grandes latifúndios, com uso extensivo do solo, emprego de técnicas rudimentares e utilização de mão de obra escrava. Como esse sistema de produção era reconhecidamente predatório, ele demandava uma constante incorporação de novas terras, causando contínua expansão de seu espaço produtivo.

Outra atividade extensiva de grande importância na conformação do espaço rural foi a pecuária, principal atividade do período colonial, que não se destinava à exportação. Ela se localizou no sertão interior, próxima a áreas de produção para o mercado externo, como o açúcar na Região Nordeste, o extrativismo na Região Norte, e a mineração na Região Sudeste. Esse deslocamento dos rebanhos para o interior se deve à proibição, no Século $\mathrm{XVI}$, de sua criação num perímetro de até 10 léguas da costa. "Essa medida foi prenhe de 
consequências, das quais a mais importante foi a separação econômica e espacial da agricultura e da pecuária, fazendo com que uma e outra adotassem obrigatoriamente práticas extensivas" (VALVERDE, 1985, p. 194)'.

Posteriormente, além da atividade pecuária e da lavoura da cana-de-açúcar, foram introduzidas outras lavouras que tiveram importância na estruturação do espaço rural do Brasil, como o algodão, o cacau e o tabaco, já exportados no Século XVIII, e o café, de enorme significado socioeconômico e geográfico para a sociedade brasileira.

Embora o café tivesse sido introduzido no Brasil, em 1727, essa lavoura só ganha importância comercial com a decadência das culturas da cana-de-açúcar, algodão e tabaco ${ }^{2}$.A partir de então, a cafeicultura, em consonância com o aumento de sua participação na economia, apresentou uma grande expansão espacial. De início, o café foi produzido na região do Vale do Paraíba, no sul de Minas Gerais e no Espírito Santo. Dali chega a Campinas, no "Oeste Velho Paulista", para então se expandir em sentido ao "Oeste Novo" (Ribeirão Preto e Araraquara) e, posteriormente, para as áreas de terra roxa do norte do Paraná e em Mato Grosso. É relevante destacar que, desde 1870/1880, o café suplantou o açúcar como principal produto agrícola de exportação, posição mantida até a década de 1930.

Esse quadro é alterado com a Grande Depressão, crise econômica em 1929, iniciada a partir da quebra da Bolsa de Valores de Nova York. Devido à superprodução da agricultura no período, aliada à forte dependência da economia brasileira com as exportações de café e agravada pelo fato de os Estados Unidos serem o maior comprador da produção cafeeira, o governo se vê na contingência de atuar mais diretamente no setor agropecuário, por meio de políticas públicas regulatórias. Foram criadas autarquias como o Instituto do Açúcar e do Álcool (1932) e o Departamento Nacional do Café (1933), que deu origem ao Instituto Brasileiro do Café (1952), com o objetivo de mediar conflitos de interesses dos diferentes subsetores produtivos e controlar a produção por meio da compra e estocagem dos excedentes. Além disso, o Banco do Brasil desempenha um papel fundamental no financiamento do setor. O Estado passa a atuar então como agente regulador, imprimindo um novo padrão de desenvolvimento econômico ao setor agropecuário, que se mantém até os dias atuais, com similitudes e diferenças significativas, conforme o período analisado.

Este trabalho abrange um período histórico/geográfico longo, em que a estrutura e a configuração do processo produtivo agropecuário se consolidam no território brasileiro, sob a regência de diversas políticas públicas. Apesar de essas políticas variarem de acordo com os diferentes governos, de comum em todo esse período foi a persistência de uma estrutura fundiária de concentração extrema, em que a grande produção monocultora predominou, a despeito de diversas iniciativas de apoio à pequena produção.

\footnotetext{
1 Segundo Valverde (1985), até meados do Século XIX, constituíram-se no Brasil três zonas principais de criação: o sertão do Nordeste; o sul de Minas Gerais; e as planícies e planaltos da Região Sul.

2 A produção da cana-de-açúcar entra em decadência a partir da concorrência das Antilhas e do açúcar de beterraba europeu. Também o algodão entra em decadência devido à produção norte-americana e, o Tabaco, com a Lei Euzébio de Queiroz, que proibia o tráfico de escravos. (BRASIL, 1850).
} 
Esta análise tem por objetivo traçar um amplo panorama da trajetória geográfica do processo de ocupação do espaço rural brasileiro. O tempo investigado varia da década de 1940, quando, após a Segunda Guerra Mundial, o Estado se redefine como principal agente de fomento da acumulação capitalista no campo e passa a atender, de modo definitivo e sistemático, demandas específicas do setor, até os dias atuais, quando o País se afirma no mundo como uma grande economia agroindustrial. Examina-se a maneira como algumas dessas transformações se concretizaram no setor agropecuário brasileiro, no intervalo entre os Censos Agropecuários 1940/2006. Para tanto, foram identificadas variáveis passíveis de serem comparadas no período em estudo: a evolução dos estabelecimentos rurais em número e área; a utilização das terras destes, considerando as áreas das principais atividades produtivas; o total de pessoal ocupado; o número de tratores e os efetivos da pecuária, sobretudo o dos bovinos.

Apesar de a análise comparativa de dados censitários por um período tão longo ficar restrita a um número limitado de variáveis estruturais, e de ser realizada em uma escala por Unidades da Federação, sua escolha deve-se ao fato de identificar padrões regionais de transformações estruturais no setor agropecuário, que levam tempo para se materializar no espaço rural brasileiro.

Desde meados dos anos 1940, a agricultura brasileira vem passando, de forma ininterrupta, por um profundo reajustamento produtivo, visando a sua modernização. Esse processo, caracterizado por diferentes etapas, ocorre por meio de uma contínua melhoria e ampliação do sistema logístico de infraestrutura de transporte e armazenagem, e, institucionalmente, por meio de políticas visando ao aumento e à diversificação das exportações e, principalmente, pela transformação da base técnica de produção do setor agropecuário. Com isso, em seu decorrer, o processo de modernização vai sendo permeado por um crescente aumento das trocas intersetoriais, o que implica a ampliação e a intensificação das condições de produção agrícola e, no limite, na transformação deste setor em um complexo agroindustrial mais completo, agora envolvendo um articulado sistema de interesses e de ações intersetoriais.

Todas essas transformações decorrem de um rearranjo técnico-econômico e territorial em que, necessariamente, não só há uma concentração da produção em determinados produtos, como, simultaneamente, ocorre uma especialização dinâmica dos lugares em que esta se realiza no espaço e no tempo. A sua forma de concretização no território varia em função da época em que ocorre, do padrão técnico-científico disponível, bem como do modo de como se dá a inserção dos diferentes países na economia-mundo e, sobretudo, das políticas públicas adotadas na consecução dos objetivos almejados.

Entre 1940 e 1950, era inquestionável a primazia das atividades agropecuárias sobre o conjunto da economia brasileira, aí compreendida não só o domínio econômico, como social, político e cultural. Nesse período, e sem se considerar os produtos pecuários, o valor da produção dos 20 principais produtos agrícolas, segundo Bernardes (1961), equivalia a $54 \%$ do valor de toda a produção industrial do País ${ }^{3}$.

\footnotetext{
3 O valor da produção agrícola considerada foi de 136,2 milhões de cruzeiros, enquanto o da produção industrial foi de 116,7 milhões, ano-base 1950. Ressalte-se que, nos cálculos da agricultura, não foram incluídos valores da atividade pecuária e que $29 \%$ do valor industrial provêm de indústrias alimentares.
} 
Apesar de sua importância, a economia agropecuária era, contudo, extremamente frágil, mantendo-se, de acordo com esse autor, em grande medida deficitária, com baixos rendimentos e instabilidade da produção tanto no tempo como no espaço.

Nas décadas de 1940 e 1950, a principal área onde ocorriam atividades agropecuárias no País formava um espaço contínuo correspondente às atuais Regiões Nordeste (com exceção dos Estados do Maranhão, Piauí e Sergipe), Sudeste e Sul. A sua produção estava concentrada, sobretudo, nestas duas últimas, sendo que, a Região Sudeste, isoladamente, detinha $42 \%$ de todas as áreas de lavouras. Só o Estado de São Paulo concentrava em torno da metade das áreas de cultivo do algodão (47\%) e do café (52\%), este último, o principal item da pauta de exportações (ANUÁRIO ESTATísTICO DO BRASIL 1950, 1951). (Mapa 1).

Mapa 1 - Evolução da lavoura temporária - 1940/2006
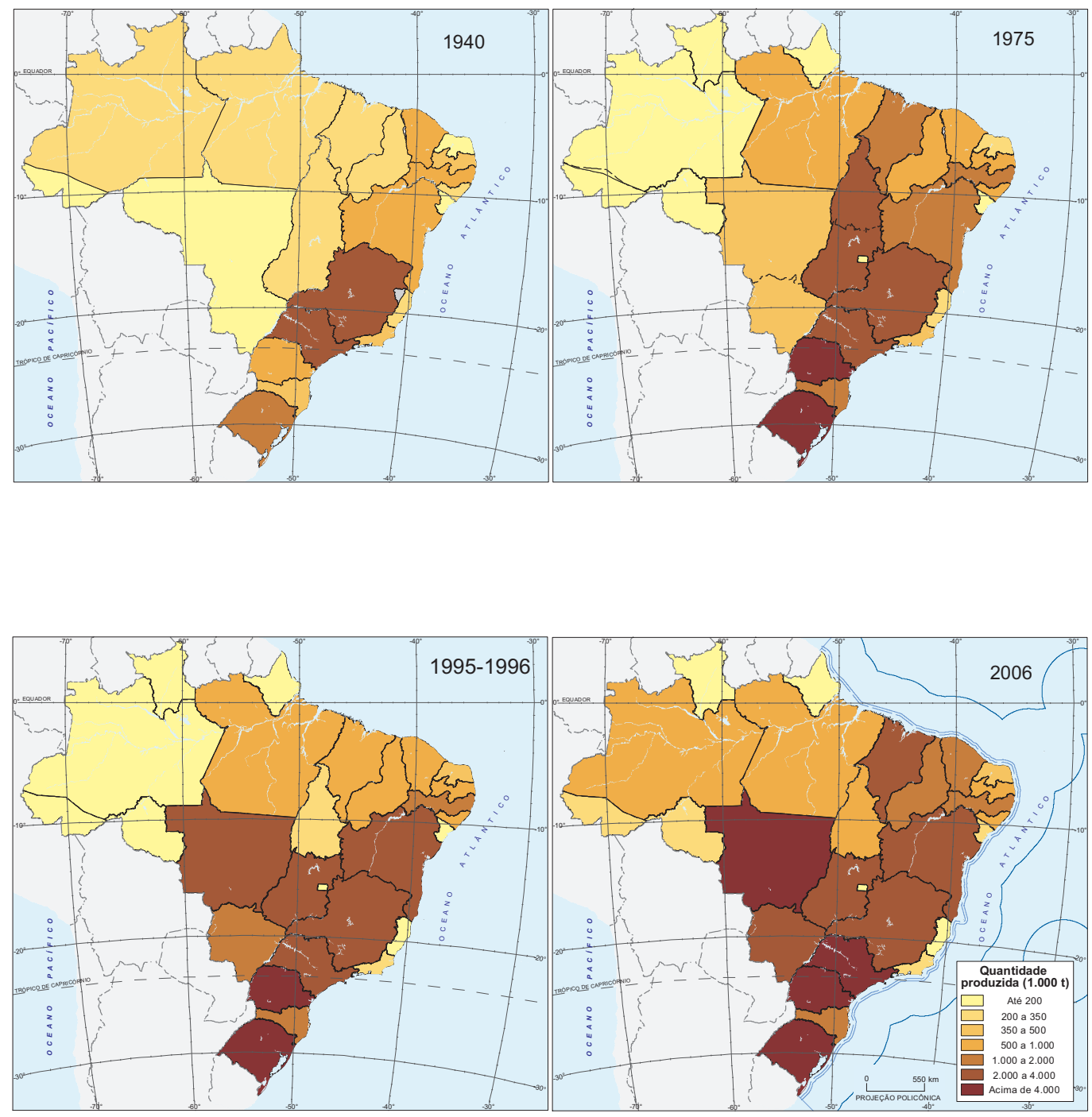

Fonte: IBGE, Censo Agropecuário 2006. 
Outras lavouras de importância comercial à época eram a cana-de-açúcar, o cacau, o arroz e o trigo. Estas culturas, ao lado das de feijão, mandioca e milho, cujo objetivo principal era a subsistência, formavam a base da atividade agrícola brasileira. Cabe destacar a importância econômica da pecuária bovina, cujo rebanho, já naquele período, era considerado o quarto maior do mundo, com um total de 44600159 de cabeças em 1950 (CENSO AGROPECUÁRIO, 1970; 2006) (Mapa 2).

\section{Mapa 2 - Evolução do número de bovinos - 1940/2006}
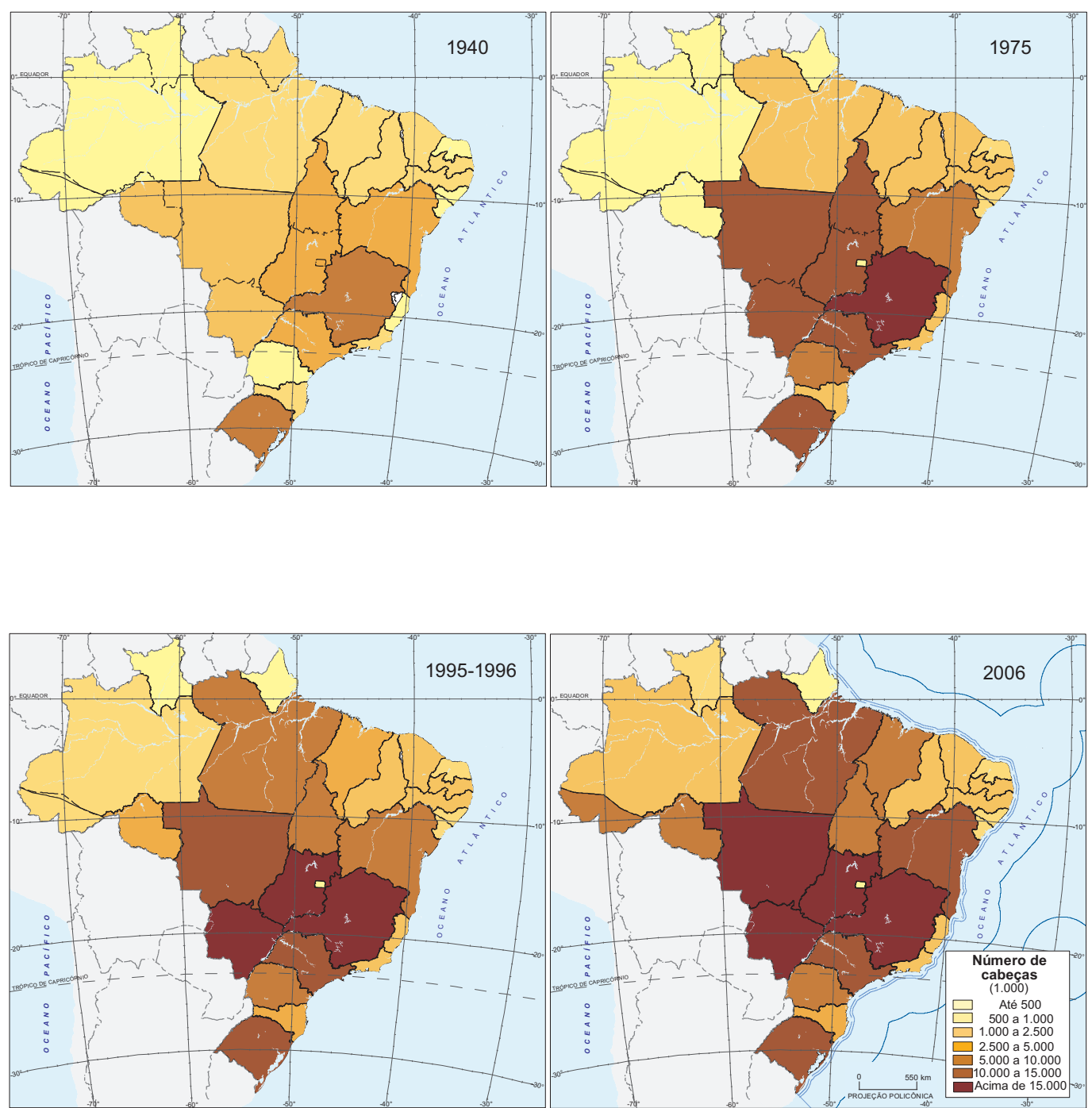

Fonte: IBGE, Censo Agropecuário 2006.

A abertura de novas áreas de pastagens foi uma das principais causas do aumento da área dos estabelecimentos verificado no período. Em "zonas de ocupação mais antiga", como Rio de Janeiro, São Paulo, Minas Gerais e Rio Grande do Sul, esse processo se deu por "um recuo da área já cultivada" com lavouras. A grande expansão da atividade pecu- 
ária, no entanto, se deu em áreas de fronteira agrícola, sobretudo, pela "incorporação aos estabelecimentos rurais de grandes trechos de campos de cerrado na Região Centro-Oeste [...], onde se verificou o maior acréscimo relativo de área total" (BERNARDES, 1961, p. 103).

Apesar de a expansão da pecuária predominar, havia também uma preocupação, por parte do governo brasileiro, de ocupar essas áreas da Região Centro-Oeste com colônias agrícolas para a produção de alimentos e matérias-primas a baixo custo. Com isso, criava-se, nos "sertões brasileiros", um mercado para produtos industrializados, direcionando-se um expressivo contingente populacional, sobretudo da Região Nordeste, para o interior do País e, ao mesmo tempo, ocupando espaços até então vazios. Visando à implantação desse projeto, foram criadas, em 1943, por iniciativa estatal, as Colônias Agrícolas Nacionais de Goiás e de Mato Grosso, que, embora não atingissem seu objetivo de criar núcleos de pequenos produtores, deram origem, respectivamente, aos municípios de Ceres e Dourados.

Outra região de fronteira agrícola, cuja ocupação se baseou na criação de colônias, foi a do Paraná. Diferentemente da Região Centro-Oeste, o projeto de colonização nesse estado, que tinha um caráter empresarial, foi, em princípio, bem-sucedido. A sua ocupação se deu com base no estabelecimento de descendentes de italianos e alemães procedentes do Rio Grande do Sul e Santa Catarina, que ocuparam pequenos lotes de terra no sudoeste e oeste do Paraná. Cabe ressaltar que, além de uma pequena policultura de alimentos, eles cultivavam a hortelã, destinada a empresas compradoras, a menta e a soja, esta última utilizada apenas como forragem verde para alimentação de animais.

Outra área de fronteira agrícola existente, na década de 1940, localizava-se no Maranhão. Diferentemente do Paraná e da Região Centro-Oeste, contudo, a frente de ocupação naquele estado apresentou um caráter "espontâneo", absorvendo um excedente populacional proveniente do semiárido nordestino. Nessas áreas, estabeleceu-se um sistema de produção agroextrativista em que se alia a agricultura de queima e o pousio com o extrativismo das amêndoas de babaçu, principal base econômica do estado. Nesse período, começa também a se intensificar a produção de arroz, cujo cultivo precedia, em parte, a formação dos pastos para a pecuária em estabelecimentos maiores.

Assim, seja em áreas consolidadas ou de expansão, a produção agropecuária dos anos 1940-1950 estava estruturada sobre uma malha fundiária extremamente desigual, na qual, ao lado de grandes estabelecimentos dedicados à pecuária e a lavouras de alto valor comercial, coexistiam pequenos estabelecimentos que praticavam uma agricultura destinada à subsistência e ao abastecimento do mercado interno. A maior parte dessa produção era obtida por meio das diferentes formas do sistema de "meação", relação de trabalho então predominante na agricultura. O trabalho assalariado, quando empregado, restringia-se a algumas grandes lavouras, sendo mais comumente utilizado nos períodos em que a safra demandava um contingente mais elevado de mão de obra.

Devido ao uso disseminado de práticas agrícolas extensivas e à ausência de uma infraestrutura de apoio, entre outros fatores, o setor agropecuário brasileiro apresentava ainda baixos rendimentos e instabilidade de sua produção, tanto no tempo como no espaço. 
Isso num período em que o País vivia um processo de urbanização e industrialização, que dependia fortemente da economia agrária.

A importância da agropecuária nesses anos estava atrelada, em grande parte, à política de substituições de importações, na qual cabia a este setor produzir alimentos para uma crescente população urbana, suprir com matérias-primas importantes setores da indústria, além de gerar divisas cambiais que viessem a financiar o desenvolvimento da própria indústria nacional. No entanto, apesar de seu papel central para o financiamento do modelo de desenvolvimento então vigente, a agricultura mantinha-se ainda atrelada a estruturas tradicionais de produção. Somente no período pós-guerra, quando há uma recuperação dos mercados internacionais, o Estado procura implementar, de forma mais decisiva, um processo de modernização de sua base técnica, pela importação de tratores e fertilizantes (GRAZIANO, 1996).

Na década de 1950, com a manutenção do modelo de substituição das importações, a agricultura permanece com o objetivo principal de abastecer os centros urbanos e, ao mesmo tempo, gerar divisas para o financiamento dos produtos importados necessários à consolidação do projeto de industrialização. No entanto, mesmo tendo ocorrido um crescimento acelerado da indústria neste período, o setor agropecuário ainda apresentava uma baixa produtividade, com as suas exportações mantendo-se calcadas na cafeicultura, cujo valor da produção exportada, entre 1949 e 1959, aumentou em 331,74\% (CENSO AGROPECUÁRIO, 1950; 1960).

Como nos anos 1950 ainda havia um predomínio amplo das tradicionais práticas de cultivo, o aumento da produção alimentar e de matérias-primas primárias dependia, em grande medida, da incorporação de novas terras ao espaço produtivo dos estabelecimentos, o que ocasionou uma significativa expansão das áreas de fronteira agrícola. Comparativamente, enquanto, no Brasil, o número e a área dos estabelecimentos aumentaram em 61,6\% e $7,6 \%$, respectivamente, no Paraná, este aumento foi de $200 \%$, no número, e de $41,7 \%$, na área dos estabelecimentos rurais. Em Goiás, onde a expansão da fronteira se deu, sobretudo, pelo crescimento da atividade pecuária, o aumento da área total de pastagens foi superior a $23 \%$, enquanto, no Brasil, foi de $13 \%$.

Com o distanciamento entre as áreas produtoras e os centros consumidores, surge a questão da infraestrutura de transportes, armazenamento e comercialização das safras, que tinham perdas calculadas em até $25 \%$ da produção embarcada (MELLO, 1979). As políticas públicas de então passam a focar seus objetivos na melhoria das condições de transporte, com a construção de grandes eixos rodoviários como a Belém-Brasília. Outra preocupação era quanto à melhoria das condições de produção. Para tanto, ampliou-se o sistema de crédito rural, de assistência técnica e os subsídios à importação de insumos modernos. Além disso, abriu-se uma linha de crédito oficial, visando à aquisição de máquinas agrícolas de fabricação nacional, sobretudo de tratores. Com efeito, entre 1950 e 1960, o número de tratores utilizados no setor agropecuário passou de 8372 para um total de 61345 unidades (FERNANDES, 2006). 
Foi, sobretudo, esse aumento do uso de tratores e a ampliação da infraestrutura de transportes o que viabilizou a continuidade da expansão das fronteiras agrícolas na década de 1950. Apesar de esses fatores de modernização terem proporcionado o alargamento de um mercado interno nacional interligado, o crescimento da agricultura manteve-se assentado na ampliação das áreas de cultivo, com a predominância de formas tradicionais de produção e trabalho ${ }^{4}$.

Nos anos 1960, época de fortes mudanças sociais e políticas no País, o projeto da industrialização com base na substituição de importações se esgota. Isso se deveu, por um lado, pela incapacidade estrutural da própria indústria nacional em atender a sua crescente demanda interna por bens de capital e matérias-primas e, por outro lado, pela incapacidade da agricultura em financiar e abastecer as necessidades de um setor urbano e um parque industrial em expansão.

Com isso, em meados dessa década, prevalecem políticas que preconizavam um modelo de "desenvolvimento associado", no qual a participação de capitais internacionais tem um papel fundamental no financiamento do desenvolvimento econômico do País. Neste contexto, adotam-se, para o setor agropecuário, políticas de modernização conservadoras, com o objetivo de estender, de forma definitiva, a dinâmica capitalista de produção ao campo, sem se alterar a estrutura fundiária preexistente.

Esse projeto, que tinha a intenção de modernizar a agricultura, aumentando e diversificando a sua produção, pela introdução e disseminação de tecnologias de ponta, apresentava dois grandes eixos para a sua concretização: primeiro expandir e ocupar os espaços ainda não integrados ao mercado nacional, por meio da criação de incentivos fiscais em favor do grande empreendimento agropecuário capitalista nacional ou estrangeiro; e segundo ampliar a concessão de créditos subsidiados, direcionados para a grande monocultura de alto valor comercial destinada à exportação ${ }^{5}$.

Graças a essas políticas, o desempenho da agricultura nos anos 1960 foi superior ao verificado na década de 1950 . Isso se traduz pelo aumento superior a $170 \%$ no número de tratores utilizados no setor, naquele decênio, onde foram empregados principalmente nas áreas de lavouras da Região Sul e do Estado de São Paulo.

Foi nesse espaço contínuo que a agricultura moderna mais se desenvolveu nos anos 1960, no contexto nacional. Além das tradicionais monoculturas de exportação do algodão e do café, nele se intensificaram e se expandiram as lavouras do milho e da soja, em caráter empresarial.

A expansão do grande empreendimento agropecuário moderno afetou muitas áreas de pequena produção agrícola, estando estas em áreas já colonizadas ou em áreas de expansão da fronteira. Isso porque o modelo de modernização conservador, ao direcionar sua política de crédito subsidiado para a mecanização, a utilização de insumos e os implementos

\footnotetext{
4 Segundo Graziano (1996), até 1960, quase 70\% do pessoal ocupado na agricultura ainda era mão de obra familiar e de parceiros, agregados e outras formas tradicionais de relações de trabalho.

5 A Lei n. 4.829, de 05.11.1965, instituiu o Sistema Nacional de Crédito Rural, principal instrumento político de incentivo à produção agropecuária.
} 
industriais, fez com que o desenvolvimento da agricultura dependesse cada vez mais de investimentos de capital. Nesse sentido, o alto custo da utilização de insumos modernos inviabilizava os pequenos agricultores, uma vez que a eles foram impostas condições de produção semelhantes às dos grandes proprietários. Em consequência da modernização da agricultura, extensas porções do espaço rural sofreram transformações na sua malha fundiária e na produção agrícola, como é o caso de diversas áreas do Paraná, onde a policultura de subsistência foi substituída por lavouras temporárias, cultivadas em grande escala, para fins de comercialização, como, por exemplo, a da soja ${ }^{6}$.

Até mesmo espaços rurais de pequena produção, distantes da principal área de agricultura moderna formada pela Região Sul e o Estado de São Paulo, sofreram modificações em seu processo de produção tradicional. Este é o caso do Maranhão, onde, nos anos 1960, projetos governamentais favoreciam a apropriação da terra por grandes empreendimentos pecuários. Com a pecuarização e a privatização das terras, extensas áreas de mata e capoeira foram transformadas em pastagens, destruindo, desse modo, o sistema agroextrativo prevalecente nesta área, ao qual estavam ligados os pequenos produtores estabelecidos há décadas nos vales dos Rios Grajaú e Pindaré.

A atividade pecuária também se expande significativamente para a Região Centro-Oeste, com as áreas de pastagens em Mato Grosso e Goiás aumentando em mais de 13000000 hectares, entre 1960 e 1970. Além dessa atividade, houve também, nesses estados, um incremento das áreas de lavouras temporárias, sobretudo no Estado de Goiás. Embora, em parte, a expansão dessas áreas esteja atribuída à lavoura do arroz, cultivo que precede a formação de pastos em áreas de fronteira agrícola, registrou-se também um aumento das áreas de milho, soja e da cotonicultura.

Essa expansão do grande empreendimento agropecuário moderno, ao mesmo tempo em que provocava uma expropriação dos pequenos produtores em diferentes áreas, rearranjava as relações de produção existentes no campo. Muitos dos antigos produtores, embora morando na periferia das cidades, são realocados no mercado de trabalho rural, na condição de trabalhadores assalariados. Isso ocorreu, sobretudo, em estados de agricultura já consolidada, como o Paraná e São Paulo. Um outro contingente de pequenos produtores, ao perder suas terras nos locais de origem, migra para áreas de expansão de fronteiras agrícolas, onde volta a se inserir, no processo produtivo, como ocupantes, pequenos arrendatários ou mesmo empregados parceiros de grandes estabelecimentos. Neste último caso, encontram-se os Estados de Goiás, Mato Grosso e Pará, que, entre 1960 e 1970, receberam um intenso fluxo migratório.

\footnotetext{
6 Embora a soja fosse conhecida, na Região Sul, antes do processo de modernização agrícola da década de 1970, ela era uma cultura secundária naquela região, sendo utilizada como alimento na suinocultura.
} 


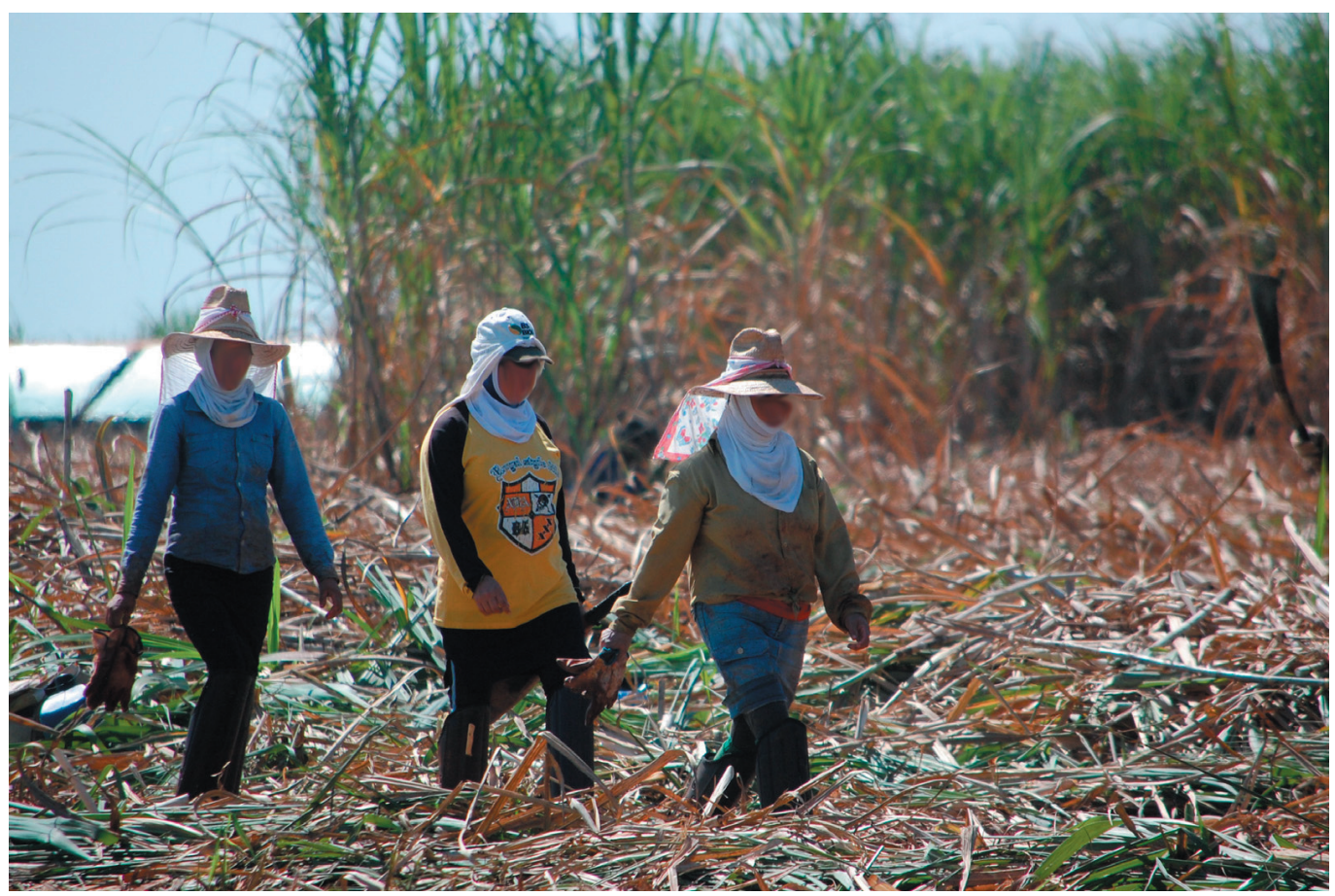

Foto 1 - Trabalhadores assalariados temporários, na colheita da cana-de-açúcar, em Ribeirão Preto, SP (2013). Foto: Luiz Sérgio Pires Guimarães.

Assim, em meados da década de 1960, a adoção de uma série de políticas públicas específicas para a chamada "modernização conservadora" da agricultura provocou importantes transformações no setor, consolidando a grande agricultura comercial, por meio da tecnicização de seus processos produtivos e de uma maior abertura ao mercado internacional. Nesse contexto, a produção agropecuária apresentou um desempenho muito superior a de décadas anteriores, devido tanto ao aumento da sua produtividade como da diversificação de suas exportações agrícolas. Ao final desse período, a situação do mercado continuava favorável, com abundância de créditos baratos, preços de insumos e bens de capital em declínio e os das commodities em alta.

Esse quadro em que o setor agropecuário se estrutura, com base na expansão e na modernização tecnológica da produção de commodities de alto valor comercial, foi consolidado ao longo da década de 1970. Nesse período, foram ampliados os investimentos públicos na infraestrutura, no armazenamento e na modernização da produção agropecuária em larga escala. Chama a atenção o aumento da mecanização do setor agropecuário entre os anos 1970 e 1980, quando a maioria dos estados mais que dobrou o número de tratores utilizados. Estados com grande produção de grãos, como, Paraná, Goiás e Mato Grosso que quintuplicaram as suas frotas nessa década. Só Mato Grosso (incluída a área do atual Mato Grosso do Sul, para efeitos de comparação) passa de um total de 4386 tratores, em 1970, para 44320 unidades, em 1980. 
Como os preços das commodities internacionais eram ainda mais favoráveis que na década anterior, ampliou-se a participação do Brasil, no mercado internacional, com o aumento das exportações de vários produtos agrícolas, entre os quais se destacam a soja, o café, o milho, a laranja (em suco), o açúcar e as carnes. Essas atividades modernizadas aumentaram, inicialmente, suas áreas na Região Sul, nos Estados de Minas Gerais e São Paulo, para, posteriormente, em meados da década, se expandirem sistematicamente por toda a Região Centro-Oeste, e, por fim, atingindo o Estado do Pará, ampliando a fronteira agrícola para áreas até então só parcialmente integradas à dinâmica de produção capitalista. Todo esse dinamismo, baseado na grande oferta de capitais existentes no mercado internacional e em uma política de crédito altamente subsidiada, deteriora-se a partir da crise do petróleo de 1979, quando ocorre uma forte retração da economia internacional.

Nos anos 1980 e até meados da década seguinte, o crescimento da dívida externa do Brasil e das taxas de juros internacionais provocou uma significativa redução dos recursos para o financiamento rural. Isso se refletiu de imediato na redução das áreas de lavouras, pastagens e pessoal ocupado na agricultura, verificada no período. Gradativamente, a política de crédito vai sendo substituída pela Política de Garantia de Preços Mínimos - PGPM, que passa a ser o principal instrumento de incentivo à expansão e ao desenvolvimento do setor agropecuário. Apesar disso, o quadro de hiperinflação obrigou o governo a elaborar um conjunto de políticas de ajustamento macroeconômico que, materializadas em uma série de planos econômicos, restringiram a plena expansão do setor agropecuário nessa década ${ }^{7}$.

Com a manutenção de um cenário macroeconômico desfavorável no Brasil, delineou-se, na década de 1990, sobretudo a partir do segundo quinquênio, a necessidade de se construir um novo quadro institucional, que permanece até o período atual e que redefiniu o espaço entre o público e o privado nos mercados agroalimentares, alinhando as novas diretrizes às exigências da Organização Mundial do Comércio - OMC. O Estado deixa, em grande medida, de ser o gestor das políticas públicas para o setor, passando a exercer o papel de principal coordenador e fiscal destas. Isso implicou a "retirada do governo de controles diretos na forma de preços ou compras e, em muitos casos, implicou no desmantelamento de serviços de extensão e, também, na eliminação de políticas setoriais mais ativas" (WILKINSON, 2003, p. 12). "Tais medidas vieram acompanhadas de uma menor proteção tarifária e de uma maior abertura ao comércio internacional, levando em vários casos a um aumento no ritmo de importação de alimentos". Visando aumentar o volume de investimentos diretos vindos do exterior, procedeu-se, conforme complementa este autor, a uma "modificação da legislação sobre os níveis de participação de capitais estrangeiros em empresas nacionais e a uma maior tolerância à remessa de lucros". (WILKINSON, 2003, p. 27). Com isso, torna possível intensificar ainda mais a modernização da agricultura, o que provocou um aumento da competitividade da produção brasileira no comércio internacional, alavancando as exportações. As consequências desse novo quadro foi a exacerbação das características do processo de modernização.

\footnotetext{
Nesse período foram sete planos de ajuste: Planos Cruzado I e II; Plano Bresser; Plano Verão; Planos Collor I e II; e finalmente, o Plano Real.
} 
Diante da nova escala mínima de capitais necessários para repor as condições da produção agropecuária, há um aumento ainda maior da concentração e da centralização dos capitais em uma gama de empresas que têm como características a forte interdependência com outros setores econômicos, não só nacionais, mas também, e cada vez mais, em nível internacional.

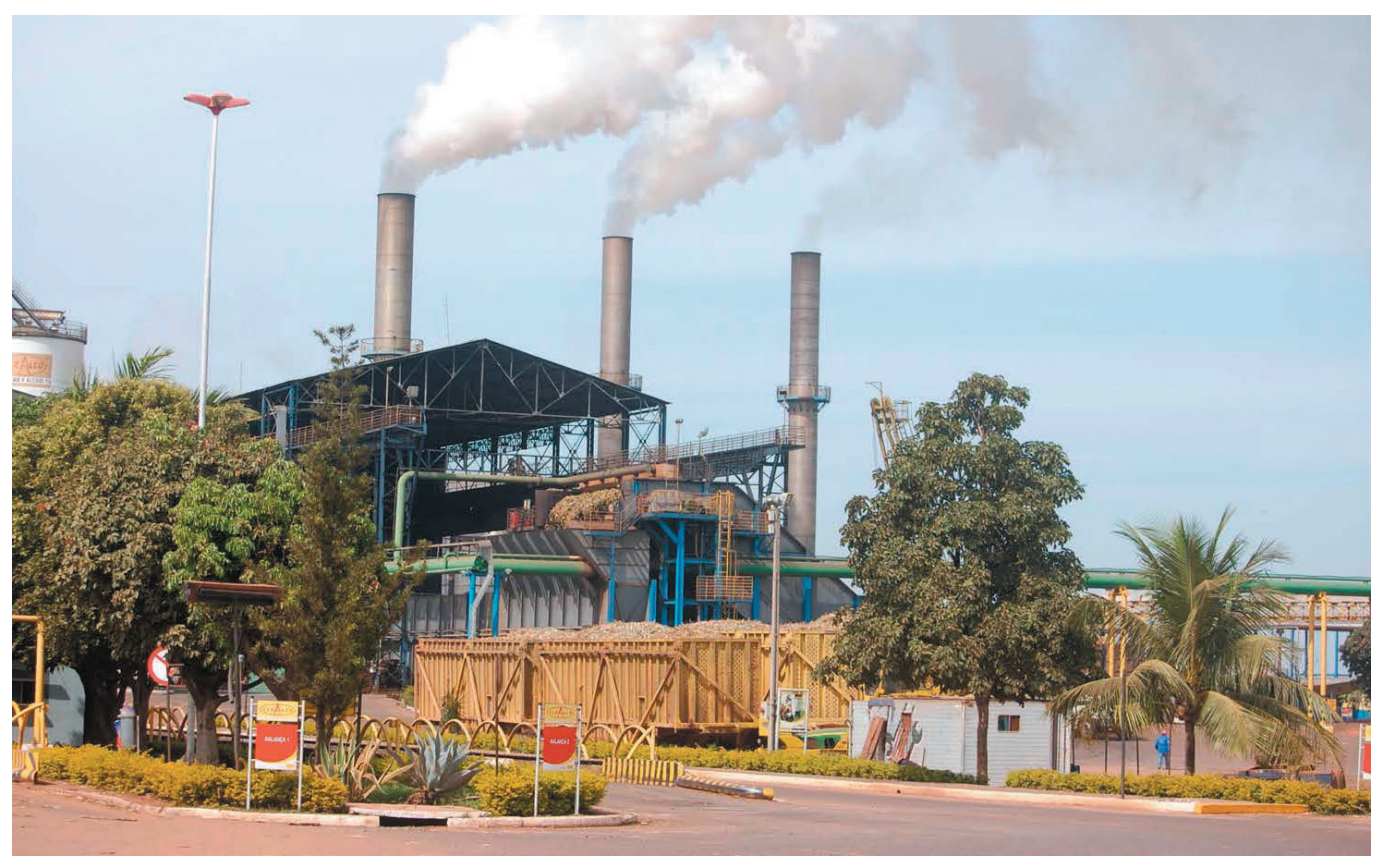

Foto 2 - Usina de cana-de-açúcar em atividade, Assaí, PR (2013).

Foto: Luiz Sérgio Pires Guimarães.

Com esse novo quadro econômico e institucional, as mudanças registradas na dinâmica da produção agropecuária entre 1996 e 2006 se refletiram no aumento do desempenho e produtividade da grande produção, notadamente das commodities. Nesse segmento de estabelecimentos, houve um grande aumento da produtividade, tanto pela disseminação do uso de tecnologia como pela expansão da área produtiva dos estabelecimentos. Registre-se que o Censo Agropecuário 2006 constatou que os estabelecimentos muito grandes, com 1000 hectares ou mais, representavam apenas $1 \%$ de todas as unidades produtivas, ocupando $45 \%$ da área destes, enquanto mais da metade dos estabelecimentos agropecuários $(52,7 \%)$ tinham menos de 10 hectares, ocupando uma área equivalente a 2,3\% da área total.

Nesse período em análise, consolida-se um dos principais objetivos do processo de modernização conservadora, iniciado nos meados dos anos 1960: a estruturação de um setor agropecuário com base em grandes estabelecimentos modernos, com uma produção de alto valor comercial, fundamentada no desenvolvimento técnico-científico, cuja lógica de investimentos varia primordialmente com as necessidades dos mercados externos. Esse modelo, com significativas diferenças regionais, se concretiza por todo o espaço rural brasileiro, transformando tanto áreas de agricultura consolidada como áreas de fronteiras agrícolas. 
Estas últimas, que vinham, desde a década de 1970, avançando pelas Regiões Centro-Oeste e Norte, formaram, em época mais recente, um grande espaço contínuo de produção no Tocantins, sul do Maranhão, sul-sudeste do Piauí e oeste da Bahia.

Diante de um cenário internacional favorável à comercialização de produtos agrícolas, observa-se, entre 1996 e 2006, um incremento das atividades produtivas, refletido na grande expansão das áreas de lavouras temporárias $(42,8 \%)$ e permanentes $(54,8 \%)$ e no aumento do rebanho bovino (15,1\%), que, em 2006, tinha um total de 176147501 cabeças, em uma área de 160042062 hectares em pastos.

Nesse último período censitário, constatou-se que áreas selecionadas do Território Nacional começam a se tornar especializadas no cultivo de determinados produtos, como a soja, a cana-de-açúcar, o milho e o algodão, obedecendo a uma dinâmica espacial que extrapola estritamente a produção agrícola e se projeta na modernização e na expansão de redes de fluxos materiais (a montante e a jusante da produção propriamente dita) e imateriais (ordens, informação, capital, serviços).

Considerando-se a cadeia produtiva da carne bovina, constata-se que o Brasil era, em 2012, o segundo maior produtor e exportador de carne bovina, além de ter o maior rebanho bovino do mundo com um total de 211279082 cabeças (CARVALHO; DEZEN; FERREIRA, 2008). A atividade pecuária no Brasil é responsável por $1 / 3$ do Produto Interno Bruto - PIB do setor agrícola, sendo o segmento destinado ao corte destacado por sua presença em um grande número de estabelecimentos distribuídos em todo o Território Nacional. Atividade tradicional no Brasil, a pecuária era, até meados da década de 1960, produzida em moldes extensivos (Mapa 3).

A partir desse período, a pecuária começa a se modernizar, incorporando tecnologia ao seu processo produtivo. Associada a áreas de expansão de fronteira agrícola, essa atividade se encontra, hoje, disseminada por quase todo o território brasileiro, principalmente nas Regiões Sul, Sudeste e Centro-Oeste, sobretudo no Estado de Mato Grosso do Sul. A concentração dessa atividade nessas regiões se deve a inúmeros fatores, entre os quais: a proximidade do principal mercado consumidor do País; e a maior presença de frigoríficos, empresas de comércio atacadista de carnes e os principais portos de exportação do País.

A rápida expansão da pecuária sobre áreas da Região Norte, em especial do Estado do Pará, tem contribuído para o agravamento da questão do desmatamento das áreas de mata na Amazônia Oriental, fazendo com que uma série de medidas e ações públicas sejam implementadas no sentido da construção de um pacto entre o setor público e os diversos segmentos que compõem a cadeia produtiva da carne, visando evitar novas frentes de expansão da pecuária sobre áreas ainda cobertas pela vegetação de florestas naquela região.

Quanto à cadeia produtiva da soja, o Brasil tem uma posição estabelecida no mercado mundial de matérias-primas agrícolas como o maior produtor de soja, tendo colhido 65848857 toneladas em uma área total de 24975258 hectares, em 2012 (PRODUÇÃO AGRÍCOLA MUNICIPAL, 2013) (Gráfico 1). 
Mapa 3 - Evolução do rebanho bovino - 2000/2012
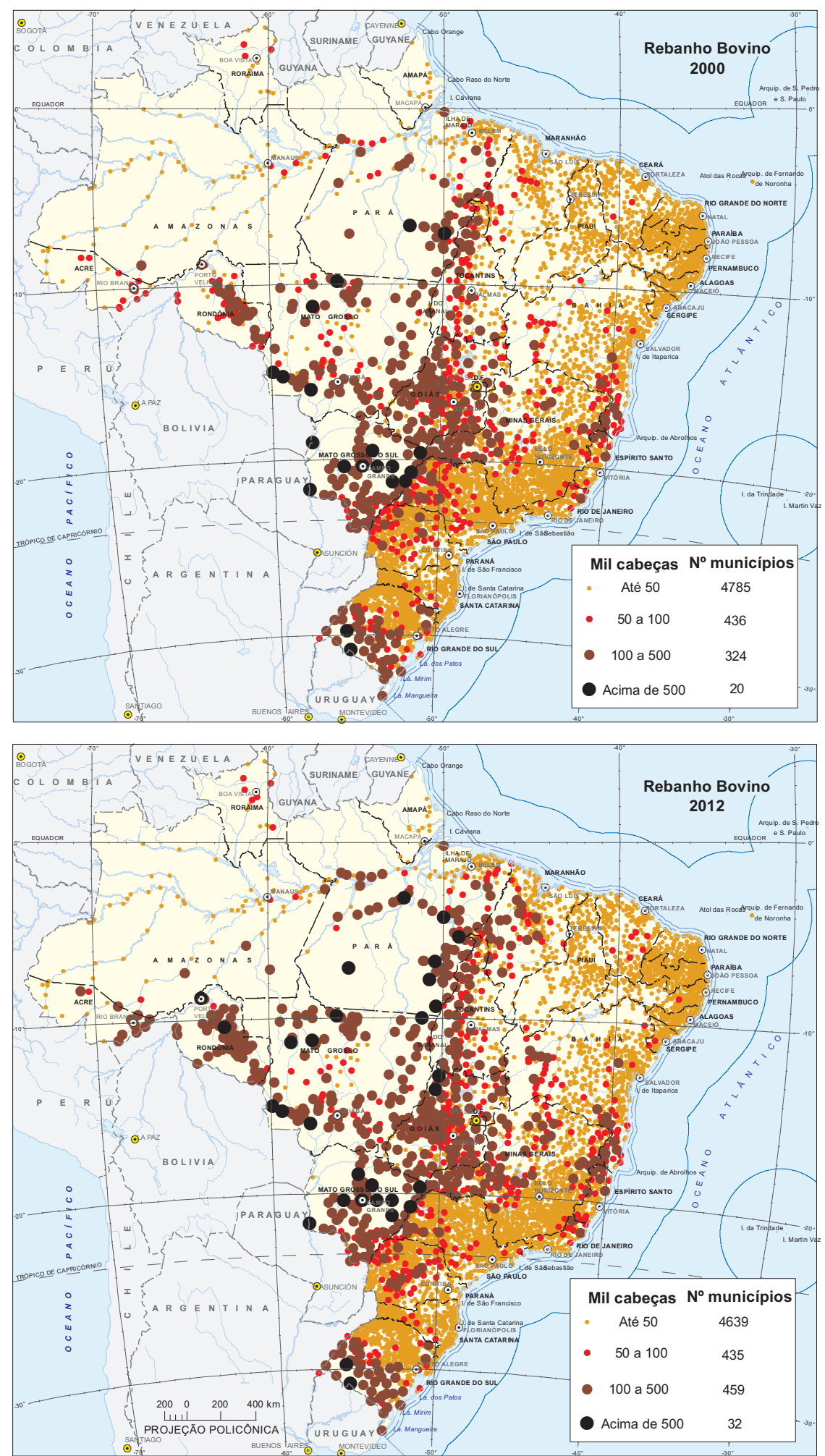

Fonte: IBGE, Censo Agropecuário 2006 


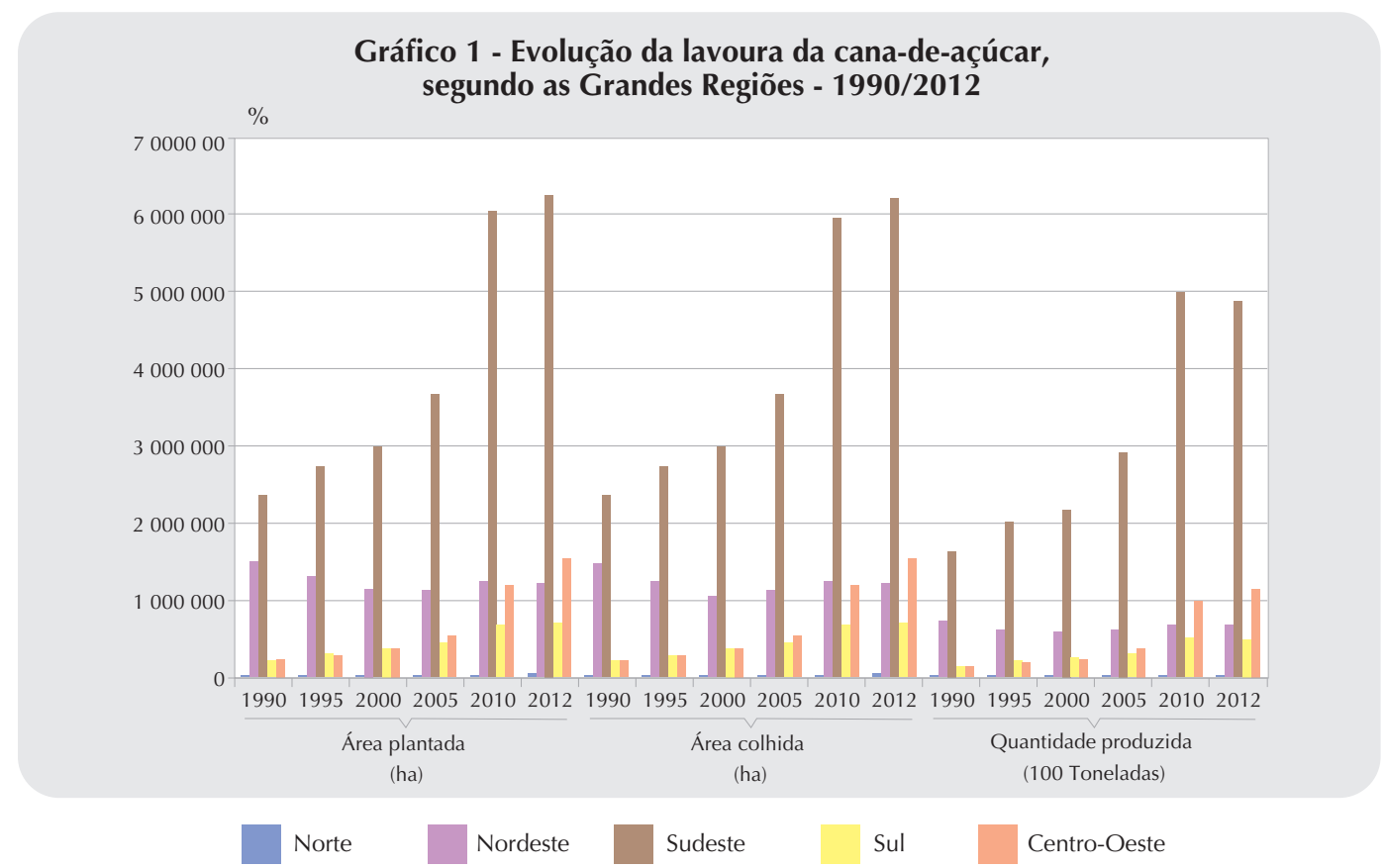

Fonte: IBGE, Produção Agrícola Municipal 1990/2012.

Conforme observado anteriormente, no Brasil, a soja foi introduzida na Região Sul, no início do Século XX, permanecendo, até os anos 1940, como uma lavoura de pouca significância, sendo cultivada por colonos do Estado do Rio Grande do Sul, com o objetivo de complementar a ração do rebanho suíno. De uma lavoura de pouca expressão, foi adquirindo importância na década de 1960, como opção de rotação ao trigo, em uma época em que políticas governamentais incentivavam a expansão da triticultura. A partir desse período, seu cultivo se expande para os Estados de Santa Catarina, Paraná e São Paulo. É, no entanto, em meados da década de 1970, com o processo de modernização da agricultura, que a soja se consolida definitivamente como a principal commoditie do agronegócio nacional, elevando seu patamar de produção e produtividade, quando se expande em direção à Região Centro-Oeste.

Apesar de sua importância, por ser uma planta originária de clima temperado, a grande expansão de sua área plantada só se concretizou quando a Empresa Brasileira de Pesquisa Agropecuária - EMBRAPA, do Ministério da Agricultura, Pecuária e Abastecimento, ao desenvolver variedades de soja que se adequavam ao clima tropical, introduziu uma ruptura tecnológica, que possibilitou a ampliação da fronteira agrícola para áreas antes consideradas inadequadas. O seu cultivo passa a ser realizado em vastas áreas da Amazônia Legal ${ }^{8}$, onde sobressaem as áreas plantadas com soja de Mato Grosso, principal produtor, Tocantins e Maranhão. Neste último estado, a área com soja localiza-se principalmente ao sul, onde forma

\footnotetext{
8 A primeira definição de Amazônia Legal foi feita pela Lei n. 1.806, de 06.01.1953, que criou a Superintendência do Plano de Valorização Econômica da Amazônia - SPVEA e definiu sua área de atuação. Atualmente, a Amazônia Legal abrange os Estados do Amazonas, Pará, Rondônia, Acre, Roraima, Amapá, Tocantins e Mato Grosso, além da porção ocidental do Maranhão limitada pelo meridiano de $44^{\circ}$.
} 
um grande espaço contínuo que atualmente já alcança o sudoeste do Piauí, que, por sua vez, é contíguo à extensa área produtora do oeste da Bahia. Embora relativamente recente, a região de sojicultura na Bahia constitui, na atualidade, uma região consolidada, com uma significativa produção. Portanto, a possibilidade de se ocuparem novos solos, com atividades agrárias rentáveis em grande escala, viabilizou a expansão da cadeia produtiva da soja para espaços regionais que, até então, em sua grande maioria, ainda mantinham sua cobertura vegetal original ou apresentavam estruturas de produção arcaicas.

A sustentabilidade econômica da cultura da soja nessas áreas de expansão foi garantida pela implantação de novas estruturas de produção viárias e energéticas, que modificaram profundamente os arranjos espaciais preexistentes.

Finalmente, juntamente com as cadeias produtivas da soja e da carne, a cadeia produtiva da cana-de-açúcar se constitui, historicamente, em uma das mais importantes do Brasil. O setor sucroalcooleiro que, em 1990, tinha produzido uma safra de 262674150 toneladas, em 2012, produziu 721077287 toneladas de cana-de-açúcar. Dada a dimensão de sua produção, a cana-de-açúcar deve ser considerada a principal lavoura geradora de biomassa energética.

Introduzida no Brasil, no Século XVI, na Região Nordeste, a cana-de-açúcar é a lavoura mais tradicional do País. Atualmente, apesar de a Região Nordeste ainda manter um importante setor sucroalcooleiro, a sua produção, em relação ao total do Brasil, era apenas de 9,4\%, em 2012. Nesse mesmo ano, a produção de cana-de-açúcar das Regiões Sudeste e Centro-Oeste, somadas, equivaliam a 83,2\% da safra brasileira. Ressalte-se que, em 2012, aproximadamente $15,7 \%$ da safra de cana-de-açúcar foi colhida na Região Centro-Oeste, região para onde tem se expandido esse cultivo, sobretudo a partir de São Paulo e do Triângulo Mineiro (Gráfico 2).

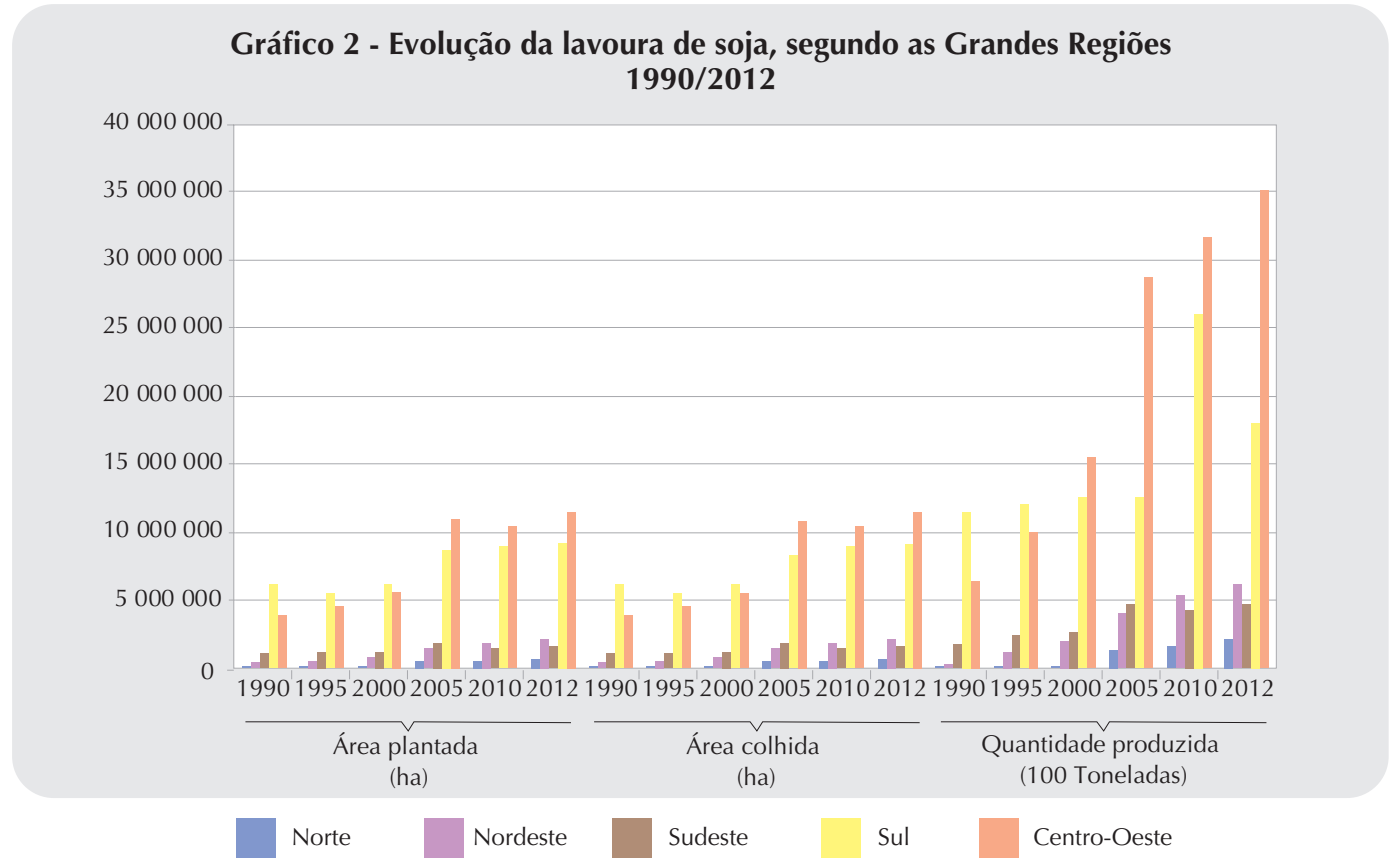

Fonte: IBGE, Produção Agrícola Municipal 1990/2012. 
Esse rearranjo espacial do setor sucroalcooleiro foi uma das transformações mais significativas no uso e na ocupação do território brasileiro no último período censitário. Essa mudança vem ocorrendo, especialmente no Centro-Sul do País, com o processo de introdução, expansão e concentração de grandes plantações de cana-de-açúcar. São Paulo, que, em 1996, já era o maior produtor nacional de açúcar e álcool, registrou a maior expansão de área plantada com esta lavoura em direção a áreas contíguas ao território paulista como as do Triângulo Mineiro, mas também as do centro-leste de Mato Grosso do Sul e, em menor escala, as do noroeste do Paraná, com um aumento expressivo da área ocupada com a lavoura canavieira.

O dinamismo do setor sucroalcooleiro nesse espaço, que forma, a partir de São Paulo, uma grande área agroindustrial consolidada, está em consonância com as demandas do mercado. A crescente procura pelo álcool combustível da cana-de-açúcar, no decênio 19962006, fez com que esse setor intensificasse o processo de centralização de sua produção nesta área, que apresenta uma excelente infraestrutura de produção, circulação e informação, potencializando, com isso, os seus ganhos de escala.

A análise dos dados censitários no período 1996-2006 indica, ainda, que a Região Centro-Oeste vem se constituindo em uma nova área de expansão da cana-de-açúcar, dentro de uma dinâmica espacial que parece não comportar mais a "esgotada fronteira" do litoral nordestino, enquanto espaço de crescimento dessa lavoura. Nesse sentido, mesmo se mantendo como importante região produtora, a tendência geral verificada para a Região Nordeste foi a de diminuição de sua participação no total do Brasil, uma vez que, com a reestruturação do setor, registrou-se uma queda da produção da agroindústria nordestina, em favor daquela localizada no Centro-Sul. Essa dinâmica provocou um recuo da área ocupada pela cultura da cana-de-açúcar na Região Nordeste, fazendo com que, nessa região, em algumas áreas, essa cultura fosse substituída por outras (mandioca, milho, frutas etc.).

Desse modo, pode-se afirmar que, na década de 2000, a reestruturação organizacional e produtiva do setor sucroalcooleiro brasileiro teve como principal estratégia a concentração e a centralização de sua produção na região Centro-Sul do País, formando e expandindo uma grande área produtora a partir de São Paulo. Essa dinâmica regional está consolidada em uma estratégia de mercado que ocasionou uma maior desigualdade entre as regiões, intensificando a desestruturação da produção do açúcar e do álcool em áreas de forte tradição no desenvolvimento da cultura da cana-de-açúcar. Esse é o caso da Região Nordeste, mas também de outras regiões, como o norte fluminense.

Com efeito, os espaços que concentraram a moderna infraestrutura do setor sucroalcooleiro tendem a se especializar na produção da cana-de-açúcar, por seu alto valor econômico, contribuindo, com isso, para o desenvolvimento de grandes monoculturas. Estas, por sua vez, desestruturam os sistemas agrícolas preexistentes, limitam as oportunidades de inserção no mercado de trabalho, contribuem para a redução da biodiversidade e concentram outros impactos ambientais, decorrentes da expansão dessas lavouras.

Nesse contexto, a análise censitária do período 1996-2006 refletiu uma realidade agropecuária marcada pela abertura da economia à concorrência internacional, pela redução e alteração das políticas públicas de apoio ao setor, por um maior aporte de capital 
estrangeiro - mas também nacional - e pelo uso de um padrão tecnológico de ponta, tanto biológico como mecânico. Destaque-se que, neste quadro, foram identificadas diversas características que marcaram a continuidade do processo de transformação técnico-econômica da agropecuária brasileira, iniciado em meados da década de $1960^{9}$.

Assim, apesar de variações locais pouco significativas, o nível de concentração da estrutura fundiária manteve-se elevado em todo o espaço agropecuário. Mesmo tendo sido reduzida a área total dos estabelecimentos, estes intensificaram suas produções. Apesar de a intensificação produtiva ter caracterizado o período, registraram-se também o avanço e a abertura de novas áreas de fronteira agrícola, no sentido norte/nordeste.

Com a valorização da atividade agropecuária, o predomínio dos estabelecimentos dirigidos pelos próprios proprietários aumentou. Apesar de o Brasil estar posicionado como um grande produtor mundial de alimentos e de matéria-prima, tendo por base uma produção agropecuária capitalista altamente tecnificada, era o trabalho familiar, e não o assalariado, a principal forma de emprego da mão de obra em 2006. Essa mão de obra, que representava $77 \%$ do total de trabalhadores rurais, de um modo geral, mantinha-se ligada à pequena produção. Esta última, apesar da heterogeneidade de situações no que diz respeito ao nível de modernização de seu processo produtivo, mantinha-se, em grande parte, atrelada ao mercado interno, voltando sua produção, basicamente, aos alimentos que compõem a cesta básica nacional.

Por fim, a série histórica da informação censitária, entre 1940 e 2006, revela que a agropecuária brasileira vem se modernizando a partir de diferentes modelos produtivos que, em comum, têm o fato de privilegiar a grande produção monocultora de alto valor comercial, destinada à exportação, enquanto a pequena produção de fraca inserção no mercado e/ou voltada à comercialização continua a ter papel relevante na produção alimentar para mercado interno. Se, em princípio, adotou-se um modelo de "substituições de importações", a partir de meados dos anos 1960, o setor rural passa a ser reconfigurado no padrão clássico da modernização conservadora, cujos princípios e estratégias locacionais definem, em grande parte, a geografia do espaço rural brasileiro na contemporaneidade.

\section{Referências}

ANUÁRIO ESTATÍSTICO DO BRASIL 1950. Rio de Janeiro: IBGE, ano XI, 1951. Disponível em: <http://biblioteca.ibge.gov.br/pt/biblioteca-catalogo?view=detalhes\&id=720>. Acesso em: fev. 2016.

BERNARDES, N. Características gerais da agricultura brasileira no século XX. Revista Brasileira de Geografia, Rio de Janeiro: IBGE, ano 49, p. 363-420, abr./jun. 1961. Disponível em: <http:// biblioteca.ibge.gov.br/visualizacao/monografias/GEBIS\%20-\%20RJ/RBG/RBG\%201961\%20 v23_n2.pdf $>$. Acesso em: jan. 2016.

\footnotetext{
9 Segundo Delgado (2012), esta transformação ocorreu principalmente no período de 1965 a 1980, caracterizado auge da "modernização conservadora".
} 
BRASIL. Lei n. 581, de 4 de setembro de 1850. (Vide Decreto n. 731, de 14 de novembro de 1850). Estabelece medidas para a repressão do trafico de africanos neste Império. Disponível em: <http://www.planalto.gov.br/ccivil_03/Leis/LIM/LIM581.htm>. Acesso em: fev. 2016.

CARVALHO, T. B.; DEZEN, S.; FERREIRA, P. C. caracterização da atividade pecuária de engorda nos principais países produtores de carne bovina. Trabalho apresentado no XLVI Congresso da Sociedade Brasileira de Economia, Administração e Sociologia Rural - SOBER, realizado em Rio Branco, 2008. Disponível em: <http://www.sober.org.br/palestra/9/571. pdf>. Acesso em: fev. 2016.

CENSO AGROPECUÁRIO 1940-2006. Rio de Janeiro: IBGE, 1940-2009. Disponível em: $<$ http://www.ibge.gov.br/home/estatistica/economia/agropecuaria/censoagro/default.shtm>. Acesso em: fev. 2016.

DELGADO, G. C. Do capital financeiro na agricultura à economia do agronegócio: mudanças cíclicas em meio século (1965-2012). Porto Alegre: Ed. da Universidade Federal do Rio Grande do Sul - UFRGS, 2012. 144 p.

FERNANDES, A. D. A dinâmica da fronteira agrícola em Goiás (1970-1985). 2006. 142 p. Dissertação (Mestrado em História)-Universidade Federal de Goiás, Goiânia, 2006.

GASQUES, J. G. et al. Desempenho e crescimento do agronegócio no Brasil. Brasília, DF: Instituto de Pesquisa Econômica Aplicada - IPEA, fev. 2004. (Textos para Discussão n, 1009). Disponível em: <http://www.ipea.gov.br/portal/images/stories/PDFs/TDs/td_1009. pdf>. Acesso em: fev. 2016.

GRAZIANO, J. da S. A Nova dinâmica da agricultura brasileira. Campinas, SP: Universidade Estadual de Campinas - UNICAMP, Instituto de Economia, 1996. 217 p.

MELLO, F. B. H. Políticas de desenvolvimento agrícola no Brasil. In: SAYAD, J. (Org.). Resenha de economia brasileira. São Paulo: Saraiva, 1979. p. 56.

MOTTA, M. Dicionário da terra. Rio de Janeiro: Civilização Brasileira, 2005. 515 p.

PORRO, R.; MESQUITA, B. A. de; SANTOS, I. de J. P. Expansão e trajetórias da pecuária na Amazônia: vales dos Rios Mearim e Pindaré - Maranhão. Brasília, DF: Ed. UnB, 2004.

PRODUÇÃO AGRÍCOLA MUNICIPAL: culturas temporárias e permanentes 2012. Rio de Janeiro: IBGE, v. 39, 2013. Acompanha 1 CD-ROM. Disponível em: <http://www.ibge.gov. br/home/estatistica/economia/pam/2012/default.shtm>. Acesso em: fev. 2016. 2014.

VALVERDE, O. Estudos de geografia agrária brasileira. Petrópolis: Vozes, 1985.

WILKINSON, J. A pequena produção e sua relação com os sistemas de distribuição. Trabalho apresentado no Seminário sobre políticas de Seguridad Alimentaria y Nutrición em América Latina, realizado em Campinas, SP, 2003. 
